\title{
THE TRUTH COMES NATURALLY! DOES IT?
}

$$
\text { Bruno Verschuere1,2, 3*, \& Shaul Shalvi4 }
$$

1. Department of Clinical Psychology, University of Amsterdam, The Netherlands

2. Faculty of Psychology and Neuroscience, Maastricht University, The Netherlands

3. Department of Psychology, Ghent University, Belgium

4. Psychology Department, Ben-Gurion University of the Negev, Israel

* Corresponding author

Dr Bruno Verschuere , Department of Clinical Psychology, University of Amsterdam,

Weesperplein 4, 1018 XA Amsterdam, The Netherlands, Phone: ++310205256799

Email: b.j.verschuere@uva.nl 


\section{THE TRUTH COMES NATURALLY! DOES IT?}

\section{Abstract}

Does the truth come naturally? And by implication, does this mean that a lie may not come as naturally as the truth? Truth-Default Theory (TDT) and the Information Manipulation Theory 2 (IMP2) diverge in their opinion on whether people's natural response is to lie or tell the truth. In line with TDT, cognitive psychology research fits supports the notion that the truth is the default in human communication. IMP2 holds that lying may come as naturally, or even more naturally than truth telling, and recent social psychology research supports this possibility. We suggest that motivation may explain the divergence between the two theories and the two lines of research. We raise the hypothesis that truth telling may be the natural response absent clear motivations to lie (hence, most human communication), and that lying may prevail as the automatic reaction when it brings about important self-profit. We hope that this hypothesis will stimulate new research that will allow for bridging the theoretical and empirical findings that seem discrepant at first, and show when the truth (vs the lie) comes naturally. 


\section{Keywords}

deception, lie detection, truth, automatic, cognitive load, cheating, ethical decision making 
Oh my goodness, is it already half past six? You realize you will be late. You jump on your bike and pedal as fast as you can. As if Murphy is involved, a policeman stops you, warning you that your bike lights are off. 'But officer, I am in a hurry. I did not realize. I simply forgot to switch on my light'.

While the denial in the example above may sound entirely plausible, it is also clear that the situation brings about the motivation to lie (e.g., to avoid penalty, or losing time). The crucial question in deception research - whether fundamental or applied - is the question of what distinguishes lie from truth. Both Truth-Default Theory (TDT) and the Information Manipulation Theory 2 (IMP2) are thus welcomed for providing well-articulated suggestions on how and when deceptive and truthful communication may differ. Here, we focus on one aspect covered in both theories: Does the truth come naturally? And by implication, does this mean that a lie may not come as naturally as the truth?

\section{Truth automaticity: Viewpoint from TDT and IMP2}

Central to the Truth-Default Theory (TDT) is the idea that we typically believe what other say. Gilbert (1991) elegantly argued that the truth is simply the most efficient way of communication. It would be a waste of time and effort to evaluate the truth status of each incoming message. Of course, the reasoning only holds if most messages are actually truthful. Important support for TDT therefore comes from data showing (1) that most people report telling the truth most of the time, and (2) the truth bias in evaluating human communication, that is, people's tendency to overestimate the chance that a message is truthful rather than deceptive. The core tenet of TDT is that '... when humans communicate with other humans, we tend to operate on a default presumption that what the other person says is basically honest (pp3)'. Note that TDT emphasizes truth default in evaluating human communication. This focus provides valuable insights in how we receive incoming messages, yet from the 
applied perspective of lie detection, it is probably more important to know whether the truth also comes naturally in the sender's behavior.

TDT Proposition \#1 that 'most communication by most people is honest most of the time' implies that humans also have a truth bias in sending information. The perspective of the sender is more fully addressed by the Information Manipulation Theory 2 (IMT2). IMT2 considers how lie production originates. IMT2 relies heavily on the idea that humans wish to maximize efficiency in all aspects of behavior, including communication. Fully embracing the efficiency perspective, IMT2 holds that deceptive communication must be efficient in terms of effort/reward ratio if not one would opt for honest communication. Indeed, 'high cognitive load is not intrinsic to deceptive discourse production (pp.29)' and 'must present cognitive efficiency advantages over truth telling within many contexts. - Even more efficient than truth telling' (pp12). Unlike TDT, IMT2 therefore does not take truth automaticity in human discourse for granted, and states that lying may even be the more natural response. We think this is an interesting point of divergence between the two theories, and now address empirical research from cognitive and social psychology speaking to this issue.

\section{Cognitive Psychology}

Using a variety of methods, researchers have tried to map the mental effort it takes to lie versus tell the truth. The most direct way has been to ask people how much effort it took them to produce a deceptive or truthful message. People find lying more difficult than truth telling (Caso, Gnisci, Vrij, \& Mann, 2005; Vrij, Semin, \& Bull, 1996). As self-report may be biased by response tendencies, most other studies used indirect measures to assess the cognitive complexity of lying and truth telling. Brain imaging studies consistently found that lying is associated with greater activity in brain regions that have been related to cognitive 
control than truth telling (Christ, Essen, Watson, Brubaker, \& McDermott, 2009; Farah, Hutchinson, Phelps, \& Wagner, 2014; Gamer, 2011). Following the logic of mental chronometry (Donders, 1868/1969), reaction times can also provide an index of the speed of performing cognitive operations. When people are instructed to answer questions as fast as possible, they are reliably slower to produce a deceptive answer than to produce a truthful answer (see e.g., Agosta, Pezzoli, \& Sartori, 2013; Debey, Verschuere, \& Crombez, 2012; Fullam, Mckie, \& Dolan, 2009; Gregg, 2007; Sartori, Agosta, Zogmaister, Ferrara, \& Castiello, 2008; Spence et al., 2001; Spence, Kaylor-Hughes, Farrow, \& Wilkinson, 2008; Suchotzki, Verschuere, Crombez, \& De Houwer, 2013; Vendemia, Buzan, \& Green, 2005; Verschuere \& De Houwer, 2011; Verschuere, Spruyt, Meijer, \& Otgaar, 2011; Walczyk, Mahoney, Doverspike, \& Griffith-Ross, 2009). People also err more often when giving deceptive responses, thereby revealing the truth. Recording of muscle activity further reveals that even for successful deceptive responding, people are initially inclined to give the truthful response (Hadar, Makris, \& Yarrow, 2012; Seymour \& Schumacher, 2009). Likewise, tracking people's arm movements using a Nintendo Wii, it was shown that there is a deviation towards the truth while giving deceptive answers (Duran, Dale, \& McNamara, 2010). In sum, using a variety of methods, cognitive psychological research suggests that the first thing to come to mind is the truth (e.g., 'Yes, I know my light is off', in the example above). Humans have the flexibility to produce an alternative, deceptive response, but this comes with a substantial and measurable cost.

\section{Social Psychology}

More recently, social psychology also began exploring whether the tendency to tell the truth prevails. Reasoning that people's natural response is to serve self-interest, social psychologists have hypothesized that lying may be one's automatic response when it clearly serves one's self-interest. Indeed, people have been found to lie more when acting under time 
pressure compared to when they had more time to deliberate on how to act (Gunia, Wang, Huang, Wang, \& Murnighan, 2012; Shalvi, Eldar, \& Bereby-Meyer, 2012). For example, in Shalvi et al.'s (2012) work, participants received a die they could privately roll and earned money based on the outcome they reported rolling (see also Halevy, Shalvi, \& Verschuere, 2014; Shalvi, Dana, Handgraaf, \& De Dreu, 2011; Shalvi, Handgraaf, \& De Dreu, 2011). Higher numbers meant higher pay. Since participants die rolls were truly private, lying was analyzed only on the aggregate level assessing if the distribution of reported outcomes deviated from the one expected if participants were reporting honestly. In one experimental condition participants were instructed to report within a given short time-frame, while in another condition no time-frame was introduced, allowing participants to report whenever they wished to do so. In two experiments, participants who had to act under time pressure not only reported their die roll outcome quicker, but also reported rolling higher outcomes compared to participants not forced to report quickly.

The finding that people lie more under time pressure, when confronted with a tempting situation in which lying may serve their self-interest, is in line with recent work showing that being depleted leads people to lie more compared to when people have more mental resources. Specifically, people lie more to secure profit, (1) after engaging in a depleting (rather than a non-depleting) task (Gino, Schweitzer, Mead, \& Ariely, 2011; Mead, Baumeister, Gino, Schweitzer, \& Ariely, 2009), (2) when there are sleep deprived (Barnes, Schaubroeck, Huth, \& Ghumman, 2011), and (3) later during the day (when they are tired) compared to when they wake up in the morning and are relatively fresh (Kouchaki \& Smith, 2014). Together, this line of work in social psychology suggests that in tempting situations, people are inclined to lie in order to boost personal profit.

\section{The power of motivation}


Not only do TDT and IMT2 diverge in their opinion on whether people's natural response is to lie or tell the truth, empirical research from cognitive versus social psychology also seem to provide radically different answers. While there are many differences between the two fields (e.g., focus on cognition versus behavior), perhaps the most notable one is the difference in motivation (see also Levine, Kima, \& Hamela, 2010). In cognitive psychology, people are typically instructed to lie. The idea is that experimenters provide such instructions to avoid ending up with an imbalance in truthful and deceptive responses, potentially confounding the lie-truth comparisons. In contrast, social psychological research typically provides people with the opportunity to either lie or tell the truth. This gap in experimental approach calls for research manipulating the extent to which lying serves self-interest (vs. not) and examine whether truth telling would be the dominant response in both cases - as suggested by cognitive psychology research and implied by TDT - or lying is the default option when it serves self-interest - as suggested by social psychology research and consistent with the cost-benefit analysis of what one has to gain (or not lose) from saying the truth (vs. lying) by IMT2.

In line with IMT2, our analysis leads us to stress the importance of mapping the circumstances under which honesty or rather deception will prevail as being the most dominant response. Motivation seems a key factor, yet several other factors seem of relevance too. As argued by McCornack (1997) the ecological validity of the cognitive psychology research paradigms can be questioned, and it is important to not only study blatant lies. but also examine the automaticity of half-truths and the effort it takes to tell wellpackaged lies. Experience with deception may also influence the cognitive costs of lying. Some people (i.e., pathological liars, psychopathic individuals) lie very frequently, and it is conceivable that practice makes perfect. What may be much more common, however, is frequent lying about specific behaviors. Most people have secrets (Kelly \& McKillop, 1996), 
and secrecy by definition involves a form of deception. Cognitive psychology research has begun to address this issue, and indicates that frequent lying with regard to specific matters may indeed erase the cognitive costs of lying (Verschuere et al., 2011).

\section{Concluding remarks}

Both TDT and IMT2 shed fascinating light on the question - does the truth come naturally? While TDT highlights people general tendency to infer honesty in others' communication, IMT2 suggests that people's production of honest vs. dishonest communication depends on the outcome of an analysis weighing costs versus the benefits of lying. Here, we surveyed recent literature, discovering a noteworthy discrepancy with cognitive psychology research supporting TDT and social psychology research supporting IMT2. In this review we suggest that motivation may be a key ingredient that could allow bridging some theoretical aspects that seem discrepant at first. We raise the hypothesis that truth telling may be the natural response absent clear motivations to lie (hence, most human communication), and that lying may prevail as the automatic reaction when it brings about important self-profit. Only future empirical investigation, which we warmly encourage, will allow assessing whether this possibility is indeed true. Such future investigation will benefit from considering the proposed approach integrating valuable insights from both TDT and IMT2. Finally, we wish to point out that testing the role of motivation in truth default status is not only of theoretical, but also practical importance. Researchers (Vrij \& Granhag, 2012) and private companies (e.g., http://www.noliemri.com/) advocate using mental effort to discriminate lie from truth. Clearly, in the forensic context, lying may serve self-interest, confirming the importance of assessing how self-interest affects truth automaticity. 


\section{References}

Agosta, S., Pezzoli, P., \& Sartori, G. (2013). How to detect deception in everyday life and the reasons underlying It. Applied Cognitive Psychology, 27, 256-262.

Barnes, C. M., Schaubroeck, J., Huth, M., \& Ghumman, S. (2011). Lack of sleep and unethical conduct. Organizational Behavior and Human Decision Processes, 115, 169-180.

Caso, L., Gnisci, A., Vrij, A., \& Mann, S. (2005). Processes Underlying Deception: An Empirical Analysis of Truth and Lies when Manipulating the Stakes. Journal of Investigative Psychology and Offender Profiling, 2, 195-202.

Christ, S. E., Essen, D. C., Watson, J. M., Brubaker, L. E., \& McDermott, K. B. (2009). The contributions of prefrontal cortex and executive control to deception: Evidence from activation likelihood estimate meta-analyses. Cerebral Cortex, 19, 1557-1566.

Debey, E., Verschuere, B., \& Crombez, G. (2012). Lying and executive control: An experimental investigation using ego depletion and goal neglect. Acta Psychologica, 140, 133-141.

Donders, F. C. (1868/1969). On speed of mental processes. Acta Psychologica, 30, 412-431.

Duran, N. D., Dale, R., \& McNamara, D. S. (2010). The action dynamics of overcoming the truth. Psychonomic Bulletin \& Review, 17, 486-491.

Farah, M. J., Hutchinson, J. B., Phelps, E. A., \& Wagner, A. D. (2014). Functional MRIbased lie detection: scientific and societal challenges. Nature Reviews Neuroscience, $15,123-131$.

Fullam, R. S., Mckie, S., \& Dolan, M. C. (2009). Psychopathic traits and deception: functional magnetic resonance imaging study. British Journal of Psychiatry, 194, 229-235. 
Gamer, M. (2011). Detecting of deception and concealed information using neuroimaging techniques. In B. Verschuere, G. Ben-Shakhar \& E. H. Meijer (Eds.), Memory detection: Theory and application of the concealed information test (pp. 90-113). Cambridge, UK Cambridge University Press.

Gilbert, D. T. (1991). How mental systems believe. American Psychologist, 46, 107-119. Gino, F., Schweitzer, M. E., Mead, N. L., \& Ariely, D. (2011). Unable to resist temptation: How self-control depletion promotes unethical behavior. Organizational Behavior and Human Decision Processes, 115, 191-203.

Gregg, A. P. (2007). When vying reveals lying: The timed antagonistic response alethiometer. Applied Cognitive Psychology, 21, 621-647.

Gunia, B. C., Wang, L., Huang, L., Wang, J. W., \& Murnighan, J. K. (2012). Contemplation and Conversation: Subtle Influences on Moral Decision Making. Academy of Management Journal, 55, 13-33.

Hadar, A. A., Makris, S., \& Yarrow, K. (2012). The truth-telling motor cortex: Response competition in M1 discloses deceptive behaviour. Biological Psychology, 89, 495-502.

Halevy, R., Shalvi, S., \& Verschuere, B. (2014). Being Honest About Dishonesty: Correlating Self-Reports and Actual Lying. Human Communication Research, 40, 5472.

Kelly, A. E., \& McKillop, K. J. (1996). Consequences of revealing personal secrets. Psychological Bulletin, 120, 450-465.

Kouchaki, M., \& Smith, I. H. (2014). The Morning Morality Effect: The Influence of Time of Day on Unethical Behavior. Psychological Science, 25, 95-102.

Levine, T. R., Kima, R. K., \& Hamela, L. M. (2010). People Lie for a Reason: Three Experiments Documenting the Principle of Veracity. Communication Research Reports, 4, 271-285. 
McCornack, S. A. (1997). The generation of deceptive messages: Laying the groundwork for a viable theory of interpersonal deception. In J. O. Greene (Ed.), Messages production (pp. 91-126). Mahwah, NJ: LEA.

Mead, N. L., Baumeister, R. F., Gino, F., Schweitzer, M. E., \& Ariely, D. (2009). Too tired to tell the truth: Self-control resource depletion and dishonesty. Journal of Experimental Social Psychology, 45, 594-597.

Sartori, G., Agosta, S., Zogmaister, C., Ferrara, S. D., \& Castiello, U. (2008). How to accurately detect autobiographical events. Psychological Science, 19, 772-780.

Seymour, T. L., \& Schumacher, E. H. (2009). Electromyographic evidence for response conflict in the exclude recognition task. Cognitive Affective \& Behavioral Neuroscience, 9, 71-82.

Shalvi, S., Dana, J., Handgraaf, M. J. J., \& De Dreu, C. K. W. (2011). Justified ethicality: Observing desired counterfactuals modifies ethical perceptions and behavior. Organizational Behavior and Human Decision Processes, 115, 181-190.

Shalvi, S., Eldar, O., \& Bereby-Meyer, Y. (2012). Honesty Requires Time (and Lack of Justifications). Psychological Science, 23, 1264-1270.

Shalvi, S., Handgraaf, M. J. J., \& De Dreu, C. K. W. (2011). Ethical Manoeuvring: Why People Avoid Both Major and Minor Lies. British Journal of Management, 22, 16-27.

Spence, S. A., Farrow, T. F. D., Herford, A. E., Wilkinson, I. D., Zheng, Y., \& Woodruff, P. W. R. (2001). Behavioural and functional anatomical correlates of deception in humans. Neuroreport, 12, 2849-2853.

Spence, S. A., Kaylor-Hughes, C., Farrow, T. F. D., \& Wilkinson, I. D. (2008). Speaking of secrets and lies: The contribution of ventrolateral prefrontal cortex to vocal deception. Neuroimage, 40, 1411-1418. 
Suchotzki, K., Verschuere, B., Crombez, G., \& De Houwer, J. (2013). Relevant stimulusresponse compatibility tasks outperform irrelevant stimulus-response compatibility tasks in detecting deception and criminal intent. Acta Psychologica, 144, 224-231.

Vendemia, J. M. C., Buzan, R. F., \& Green, E. P. (2005). Practice effects, workload, and reaction time in deception. American Journal of Psychology, 118, 413-429.

Verschuere, B., \& De Houwer, J. (2011). Detecting concealed information in less than a second: Response latencies-based measures. In B. Verschuere, G. Ben-Shakhar \& E. Meijer (Eds.), Memory detection: Theory and application of the Concealed Information Test. Cambridge: Cambrdige University Press.

Verschuere, B., Spruyt, A., Meijer, E. H., \& Otgaar, H. (2011). The ease of lying. Consciousness \& Cognition, 20, 908-911.

Vrij, A., \& Granhag, P. A. (2012). Eliciting cues to deception and truth: What matters are the questions asked. Journal of Applied Research in Memory and Cognition, 1, 110-117.

Vrij, A., Semin, G. R., \& Bull, R. (1996). Insight into behavior displayed during deception. Human Communication Research, 22, 544-562.

Walczyk, J. J., Mahoney, K. T., Doverspike, D., \& Griffith-Ross, D. A. (2009). Cognitive Lie Detection: Response Time and Consistency of Answers as Cues to Deception. Journal of Business and Psychology, 24, 33-49. 


\section{Bio}

Bruno Verschuere is Associate Professor of Forensic Psychology at the University of Amsterdam (The Netherlands). He is also affiliated to Ghent University (Belgium) and Maastricht University (The Netherlands). He studies lie detection. Together with Gershon Ben-Shakhar and Ewout Meijer, he has edited Memory Detection: Theory and application of the concealed information test (2011; Cambridge, UK: Cambridge University Press).

Shaul Shalvi is a faculty member at the psychology department at Ben-Gurion University. He studies ethical decision making and processes underlying it, using social psychological and behavioral economic methods. 